\title{
A Molecularly Imprinted Polymer for the Selective Solid-Phase Extraction of Ibuprofen from Urine Samples
}

\author{
Afef Lagha, Nafaa Adhoum and Lotfi Monser ${ }^{*}$ \\ Université de Carthage, Institut National des Sciences Appliquées et de Technologie, Centre Urbain Nord, B.P. No. 676, \\ 1080 Tunis Cedex, Tunisia
}

\begin{abstract}
A molecularly imprinted polymer (MIP) was synthesized and evaluated to selectively extract ibuprofen, a nonsteroidal anti-inflammatory drug (NSAID), from human urine. The synthesis of the MIP was performed in dimethylformamide with acrylamide as functional monomer, ethylene glycol dimethacrylate as the cross linker and ibuprofen template as the target drug. The performance of the synthesized MIP as solid phase extraction (SPE) packing to recognize and bind ibuprofen was evaluated against other structurally related NSAIDs such as naproxen and ketoprofen. Using a mixture of acetonitrile-water $(1 / 9 \mathrm{v} / \mathrm{v})$ as a solvent for ibuprofen the binding recovery at approximately $90 \%$ was obtained for developed MIP in optimized conditions. Batch rebinding capacity of ibuprofen was determined from the derived Freundlich isotherm and was found to be $1.45 \mu \mathrm{mol} \mathrm{g}{ }^{-1}$. Furthermore, a higher selectivity of developed MIP for ibuprofen over structurally related analogues was observed. The synthesized MIP has enabled the direct percolation of humane urine and the easy elimination of endogenous compounds from it with simple aqueous washing of the MIP-SPE packing. HPLC analysis has confirmed the high extraction recovery (ca. $85 \%$ ) of ibuprofen from such urine samples with use of proposed MIP-SPE system.
\end{abstract}

Keywords: Molecular imprinted polymer, solid phase extraction, ibuprofen, HPLC.

\section{INTRODUCTION}

Non-steroidal, anti-inflammatory drugs (NSAIDs) are the analgesics used most commonly across the world today [1]. They are used mainly to treat inflammation and fever in animal and human species, although they can lead to serve toxic side effects in cases of over dose or chronic abuse [2]. Solid-phase extraction (SPE) constitutes a powerful method for the extraction and the purification of compounds contained in complex matrices. However, the extraction using reversed phase cartridges is based on the development of mainly hydrophobic interactions that lead to the coextraction of many interfering compounds. Improvements can be achieved by the use of molecularly imprinted polymers (MIPs). These adsorbents have attracted considerable interest as selective SPE materials in many chemical, biological and environmental areas. They possess specific cavities designed for a target analyte allowing a retention mechanism based on molecular recognition. The MIPs are used in several fields, such as sensors, catalysis, enantiomeric separation and SPE [3]. Nowadays, MIPs have been largely applied to the extraction or to clean up of target analytes from various complex matrices such environmental, biological, food and pharmaceuticals [4-6]. Concerning the pharmaceutical field, many examples deal with the extraction of a drug by MIP from tablets [7], plasma [8-10], serum [11], or from urine [12-15]. MIPs can be synthesized by three different imprinting approaches: the non covalent, the covalent and the semi-covalent methods. However, their

*Address correspondence to this author at the Université de Carthage, Institut National des Sciences Appliquées et de Technologie, Centre Urbain Nord, B.P. No. 676, 1080 Tunis Cedex, Tunisia; Tel: 0021671703717 ;

Fax 0021671704329; E-mail: lotfi.monser@insat.rnu.tn synthesis procedures used for SPE are mainly based on a non-covalent interactions (such as hydrogen bonds or ionic interactions) between a target molecule (template) and functional monomers that polymerize in a porogen solvent in the presence of a cross-linker and initiator. Once the template is removed, selective molecular recognition sites often described as three-dimensional shapes in the polymer are available for the selective rebinding of the target molecule and some structurally related compounds $[16,17]$.

The aim of the present work was to demonstrate the feasibility of using a molecular imprinting solid phase extraction (MISPE) cartridge for the selective clean-up and quantification of trace amounts of ibuprofen in human urine. Following a conventional non-covalent imprinting protocol, several binding rebinding parameters have been evaluated in an attempt to extract selectively ibuprofen from biological samples.

\section{EXPERIMENTAL}

\subsection{Materials}

A HPLC grade acetonitrile (AcN), methanol, acetic acid and dimethylformamide (DMF) were obtained from Prolabo (Paris, France). Ibuprofen, ketoprofen \& naproxen (Fig. 1) acrylamide, ethyleneglycol dime-thacrylate, 2-vinyl pyridine, were purchased from Sigma-Aldrich (St-Quentin, Fallavier, France). Analytical grade phosphoric acid was purchased from Prolabo (Paris, France). Azo-isobutyronitrile was purchased from MERCK-Schucha-rdt. Ultra pure Water (resistivity > $18 \mathrm{M} \Omega$ ) was drawn from a Milli-Q Water purification system (Millipore, USA).

\subsection{Instrumentation}

High performance liquid chromatography (HPLC) analysis was performed on a Beckman LC system (Beckman 
Instruments Inc., USA). The system was consisted of a binary pump model 125 , a Rheodyne 7725 injector with a 10 $\mu \mathrm{L}$ loop and a spectrophotometer detector (Model 166) set at $254 \mathrm{~nm}$. The chromatographic data was collected and analysed using GOLD NOUVEAU software. Separations were performed on a $25 \mathrm{~cm} \times 4.6 \mathrm{~mm}, 5 \mu \mathrm{m} \mathrm{C18}$ column (ExcelSpher). The mobile phase was a mixture of acetonitrile and $\mathrm{H}_{2} \mathrm{O}$ containing $0.05 \mathrm{M}$ phosphoric acid $(60 / 40(v / v))$ and the flow was maintained at $1.0 \mathrm{~mL} \mathrm{~min}^{-1}$. Ibuprofen calibration curve was constructed at the following concentration range : 5-100 $\mathrm{mg} \mathrm{L}^{-1}$.

\subsection{Preparation of the Molecularly Imprinted Polymer}

A non-covalent molecular imprinting approach was followed to prepare the MIP and the non imprinted polymer (NIP). The pre-polymerization mixture contains $206.3 \mathrm{mg}$ of ibuprofen dissolved in $4 \mathrm{~mL}$ of DMF. An amount of 284.3 mg of acrylamide was added to the previous solution. The mixture was stirred for $5 \mathrm{~min}$ at ambient temperature. To this $4.2 \mathrm{~mL}$ of ethyleneglycol dimethacrylate (EGDMA) was added and the mixture stirred for $5 \mathrm{~min}$ at room temperature. Then $50 \mathrm{mg}$ of azo-isobutyronitrile (AIBN) was added and the mixture was stirred for further $10 \mathrm{~min}$. Finally, the mixture was sonicated for $10 \mathrm{~min}$ and sparged with nitrogen for $5 \mathrm{~min}$. After $16 \mathrm{~h}$ of thermopolymerisation at $60{ }^{\circ} \mathrm{C}$, the resultant hard polymer was removed. Then, the rigid polymer was ground with a pestle into a mortar. To remove the template bound within the polymer matrix, the resulting powder was washed for $24 \mathrm{~h}$ with a mixture of methanol and acetic acid $(90 / 10 v / v)$ using Soxhlet extraction. The washing procedure was repeated until no more ibuprofen could be detected in the washing solution. The extracted particles were then washed with methanol then with water to remove residual acetic acid followed by oven drying. In parallel, a NIP was also synthesized, in the absence of template, following the same procedure described above.

\subsection{Batch Rebinding Studies}

For batch rebinding studies, a $30 \mathrm{mg}$ of the dry MIP and NIP particles was placed in a $25 \mathrm{~mL}$ volume Erlenmeyer and incubated for $4 \mathrm{~h}$ with $10 \mathrm{~mL}$ solution of ibuprofen $\left(20 \mathrm{mgL}^{-1}\right)$. Two solvent mixtures were tested: $\mathrm{AcN} / \mathrm{H}_{2} \mathrm{O}$ and DMF/ $\mathrm{H}_{2} \mathrm{O}$. The ratio of $\mathrm{AcN} / \mathrm{H}_{2} \mathrm{O}$ and $\mathrm{DMF} / \mathrm{H}_{2} \mathrm{O}$ mixture was varied from 10 to $100 \%$. After the period of incubation, the supernatant was removed, filtered and analyzed by HPLC in order to measure the residual ibuprofen (amount not bound).

\subsection{Sorption Kinetics}

For kinetic studies, $50 \mathrm{mg}$ of polymer was placed in an Erlenmeyer containing $25 \mathrm{~mL}$ of ibuprofen $\left(100 \mathrm{mg} \mathrm{L}^{-1}\right)$ prepared in $\mathrm{AcN} / \mathrm{H}_{2} \mathrm{O}(1 / 9 v / v)$. The solution was shacked at room temperature with a speed of $150 \mathrm{rpm}$. At predetermined intervals of time (each $5 \mathrm{~min}$ ), solutions were taken and analyzed for the final concentration of ibuprofen. The adsorption amount of ibuprofen $\left(Q_{t}: \mathrm{mg} \mathrm{g}^{-1}\right)$ at time $t$ (h), was calculated by difference between initial and final concentrations. All experiments were conducted in triplicate

and results reported here were the mean values. The following equation was used to calculate the equilibrium of ibuprofen uptake:
$\mathrm{Q}_{\mathrm{t}}=\mathrm{V}\left(\mathrm{C}_{0}-\mathrm{C}_{\mathrm{t}}\right) / \mathrm{W}$

where $\mathrm{Co}$ is the initial concentration $\left(\mathrm{mg} \mathrm{L}^{-1}\right)$ of ibuprofen and $C_{t}$ is the concentrations at time $t, V$ is the volume of solution and $\mathrm{W}$ is the mass of adsorbent in the mixture.

\subsection{Solid Phase Extraction (SPE) Studies}

In order to establish the optimum conditions under which the template can be recognized by the corresponding MIP, a standard solution of ibuprofen was initially prepared in various proportions (10-100\%) of $\mathrm{AcN} / \mathrm{H}_{2} \mathrm{O}$ and $\mathrm{DMF} / \mathrm{H}_{2} \mathrm{O}$ mixture. To a $3 \mathrm{~mL}$ empty polypropylene solid phase extraction cartridges, $200 \mathrm{mg}$ of the dry polymer (or corresponding control polymer NIP) was packed between two polypropylene frits. Before analyte loading, the polymer was conditioned with $1 \mathrm{~mL}$ methanol, $1 \mathrm{~mL}$ acetonitrile and 1 $\mathrm{mL} \mathrm{H}_{2} \mathrm{O}$. In the loading step, $2 \mathrm{~mL}$ of ibuprofen solution (20 $\mathrm{mg} \mathrm{L}^{-1}$ ) prepared in a mixture of $\mathrm{AcN} / \mathrm{H}_{2} \mathrm{O}$ (10/90) was passed through the cartridge. The washing step includes 1 $\mathrm{mL}$ of AcN containing $1 \%$ triethylamine (TEA). Finally, ibuprofen was eluted with $1 \mathrm{~mL}$ of methanol.

Urine samples were diluted with acetonitrile in order to precipitate proteins (if existed) and were then filtered through a $0.22 \mu \mathrm{m}$ syringe filter and were kept in the freezer $\left(\cong-10^{\circ} \mathrm{C}\right)$ until their use. Before analysis, $10 \mathrm{~mL}$ of urine samples were loaded onto the conditioned MIP cartridge. After a washing step, ibuprofen was recovered with methanol.

\section{RESULTS AND DISCUSSION}

\subsection{Rebinding Studies}

DMF solvent was used for the recognition ability of the MIP and NIP. Due to the polar aprotic nature of this solvent, it was expected [18] that DMF would be more compatible with rebinding in aqueous environments than less polar solvents such as toluene or dichloromethane. DMF is classified as having a medium solvent strength ability to form hydrogen bonds.

Firstly, the rebinding was assessed in the solvent in which the MIP was prepared, i.e. DMF. Fig. (2) shows that the rebinding capacity was varied from 70 to $80 \%$ for ibuprofen in DMF at a concentration range from 10-100 mg $\mathrm{L}^{-1}$. The results illustrate that the MIP showed higher affinity (70\% higher) for ibuprofen than NIP indicating that the MIP was really imprinted.

Furthermore, the rebinding of ibuprofen to MIP was assessed in a mixture of aqueous-organic system by increasing the ratio of $\mathrm{DMF}$ and $\mathrm{AcN}$ from 10 to $100 \%$. It was necessary to include DMF or AcN in each rebinding solution because of the relative low solubility of ibuprofen in water. The percentage of rebinding is defined as the quantity of ibuprofen present in the supernatant subtracted from the initial added concentration. Fig. (3) presents the percentage of rebinding of ibuprofen on the MIP and the corresponding control polymer NIP at different ratios of DMF Fig. (3a) and AcN Fig. (3b) added in the rebinding solution. According to 
<smiles>CC(C)Cc1ccc(C(C)C(=O)O)cc1</smiles>

Ibuprofen<smiles>COc1ccc2cc(C(C)C(=O)O)ccc2c1</smiles>

Naproxen<smiles>CC(C(=O)O)c1cccc(C(=O)c2ccccc2)c1</smiles>

Ketoprofen

Fig. (1). Structure of ibuprofen and its structural analogues naproxen and ketoprofen.

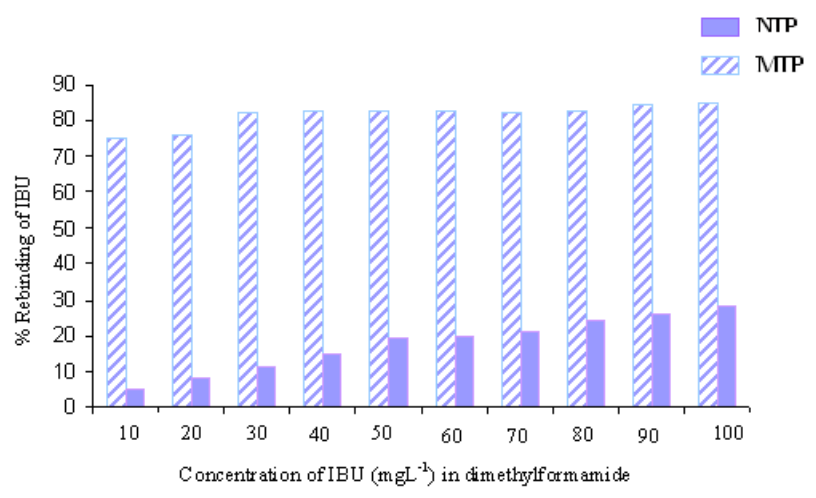

Fig. (2). Percentages of rebinding capacity of MIP and NIP at different ibuprofen concentrations.

the results obtained rebinding was found to be approximately constant $(\approx 90 \%)$ at different percentage of DMF, however, AcN showed higher rebinding capacity when lower ratios of $\mathrm{AcN}$ were included in the rebinding solution. At a percentage greater than $30 \%$ acetonitrile, a drop in the specific rebinding of approximately $40 \%$ was observed. At higher ratios of $\mathrm{AcN}$, the achieved rebinding percentage was only $20 \%$. We can conclude that the rebinding is solvent specific and that the conditions for rebinding are driven by aqueous rather than the organic solvent. As rebinding had already been shown to be efficient in DMF, acetonitrile was chosen as it is also a polar aprotic solvent and also due to its expected compatibility with the $\pi-\pi$ interaction environment [18].
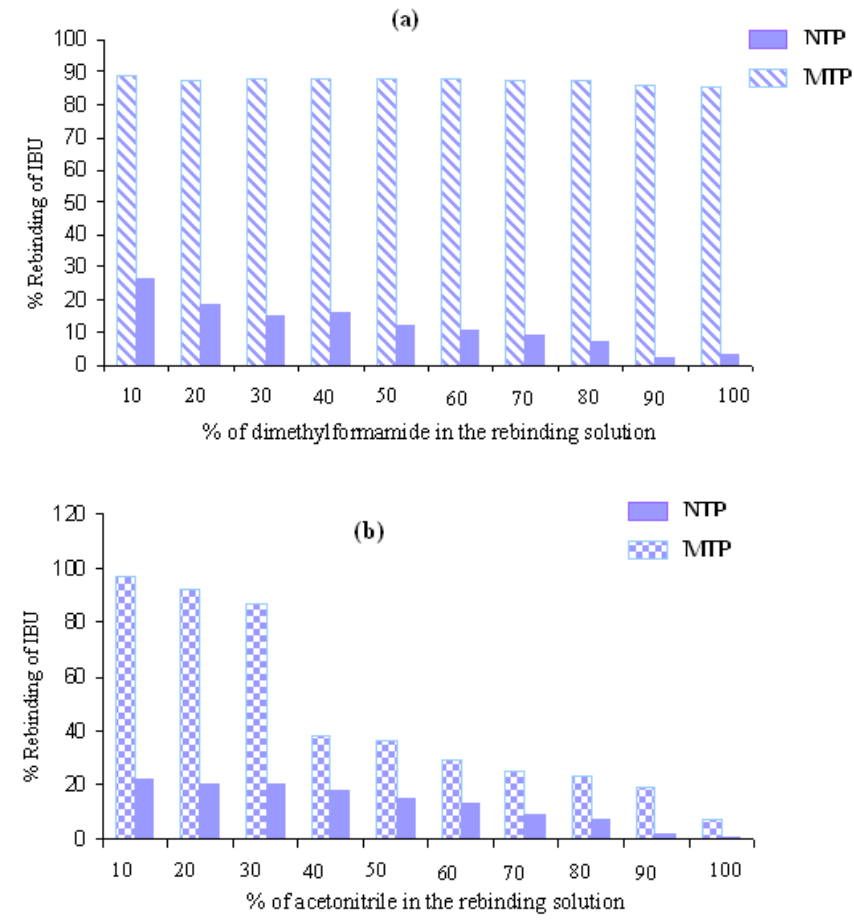

Fig. (3). The effect of increasing ratios of DMF (a) and AcN (b) as the rebinding solution on ibuprofen rebinding percentage using MIP and NIP. Experiments were carried out in batch mode using $30 \mathrm{mg}$ of polymer and $10 \mathrm{~mL}$ of ibuprofen solutions. Samples were agitated for $4 \mathrm{~h}$ at $25^{\circ} \mathrm{C}$.

\subsection{Adsorption Kinetics}

The initial concentration of ibuprofen and the amount of polymer used were kept constant during kinetic studies. As can be seen from Fig. (4), the removal rate of ibuprofen was rapid initially and then slowed down gradually until it attained equilibrium beyond which there was no significant increase in the removal rate. The initial rapid adsorption was attributed to the participation of specific functional groups, macro and micropores and active surface sites in the adsorption of ibuprofen molecules [19]. A major fraction of ibuprofen was removed within the first 15 to 20 minutes. Then, adsorption quantity increased gradually to reach approximately $43 \mathrm{mgg}^{-1}(86 \%)$ at the end of $1 \mathrm{~h}$ contact time and remained more or less constant at around $46 \mathrm{mgg}^{-1}$ even after a contact time of $24 \mathrm{~h}$.

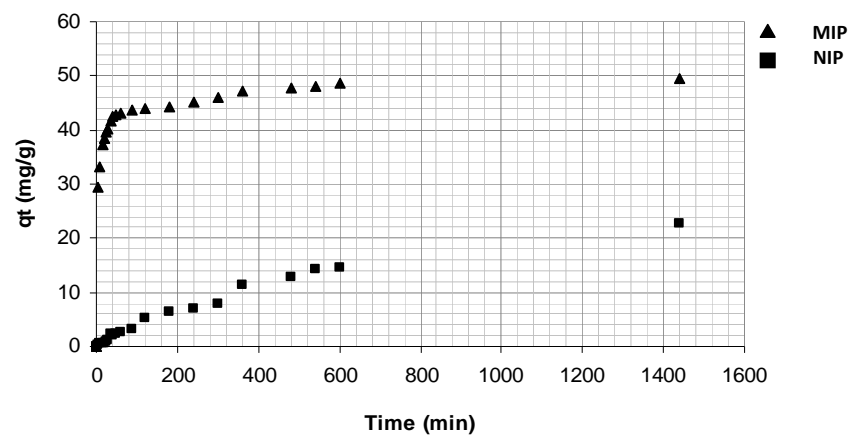

Fig. (4). Equilibrium time of ibuprofen onto MIP and NIP. Experiments were carried out in batch mode using $50 \mathrm{mg}$ of polymer and $25 \mathrm{~mL}$ of $100 \mathrm{mgL}^{-1}$ ibuprofen in $\mathrm{AcN} / \mathrm{H}_{2} \mathrm{O}(1 / 9$ $(\mathrm{v} / \mathrm{v}))$. Samples were agitated for $24 \mathrm{~h}$ at $25^{\circ} \mathrm{C}$. 
In contrast, the adsorption of ibuprofen by the NIP within the first few minutes does not exceeded $5 \mathrm{mgg}^{-1}$ and after approximately $24 \mathrm{~h}$ it attained $22 \mathrm{mgg}^{-1}$ as maximum for the same contact time. The adsorption amount by the NIP was due to the presence of non-specific interactions.

\subsection{Adsorption Isotherm}

Adsorption isotherms are useful in understanding the adsorption interaction mechanism of the template with the MIP surface. The obtained data of adsorption isotherm equilibrium was analyzed using the Langmuir, Schatcard and Freundlich isotherm models [20-22]. The experimental data for various studied were fitted better with the rearranged Freundlich isotherm model over the Langmuir or Schatcard as the experimental data fall on a straight line when plotted in a $\log B$ vs $\log F$ format. The rearranged Freundlich model [20] describes $\mathrm{B}$ as a power function of $\mathrm{F}$, according to equation (2):

$\mathrm{B}=\mathrm{aF}^{\mathrm{m}}$

The equation (2) has two parameters, $a$ and $m$, of physical meaning which reflect the distribution of binding sites of different binding strength that are present in the polymer. The term $a$ is a Freundlich parameter related to the binding affinity and the term $m$ is the heterogeneity index [21] with values from zero to one, by one indicating homogeneity of the sites. This empirical equation is suitable for highly heterogeneous surfaces [20, 21]. The Freundlich isotherm equation can be rearranged to a linear form:

$\log \mathrm{B}=\mathrm{m} \log \mathrm{F}+\log \mathrm{a}$

The plot of $\log B$ against $\log F$ allows for the determination of $a$ and $m$ by linear regression (Fig. 5). Experimental sorption parameters $\left(\mathrm{m}, \mathrm{a}, \mathrm{R}^{2}\right)$ of Freundlich model for MIP and NIP are presented in Table 1. The heterogeneity index $m$ obtained for the NIP is higher than that of the MIP, which is in agreement with previous study [22] that revealed the comparison of imprinted polymers with non imprinted polymer.

As can be seen from these results, the lower $m$ value of MIP indicates a more heterogeneous property than that of NIP. These observations could be attributed to the formation of imprints on the MIP surface. However, the obtained value of $m$ for the NIP is sufficiently distant from the unity indicating the role of heterogeneity of the adsorption sites presents in the polymer. Within this diversity, we can suppose that certain adsorption sites of NIP have an affinity towards ibuprofen equivalent to that of sites found in the MIP.

\subsection{Solid Phase Extraction Studies}

MIPs sorbents were evaluated in aqueous media by using the extraction procedure previously optimized in this medium [18]. It consists of the percolation of $0.5 \mathrm{~mL}$ of ibuprofen solutions $\left(5-200 \mathrm{mgL}^{-1}\right)$ through a cartridge of MIP or NIP. After a washing step with $1 \mathrm{~mL}$ of acetonitrile containing $1 \%$ triethylamine, ibuprofen was eluted with $1 \mathrm{~mL}$ of methanol. The analyte was strongly retained on the MIP and the recovery of ibuprofen from the MIP and its correspondent control polymer is shown in Fig. (6).
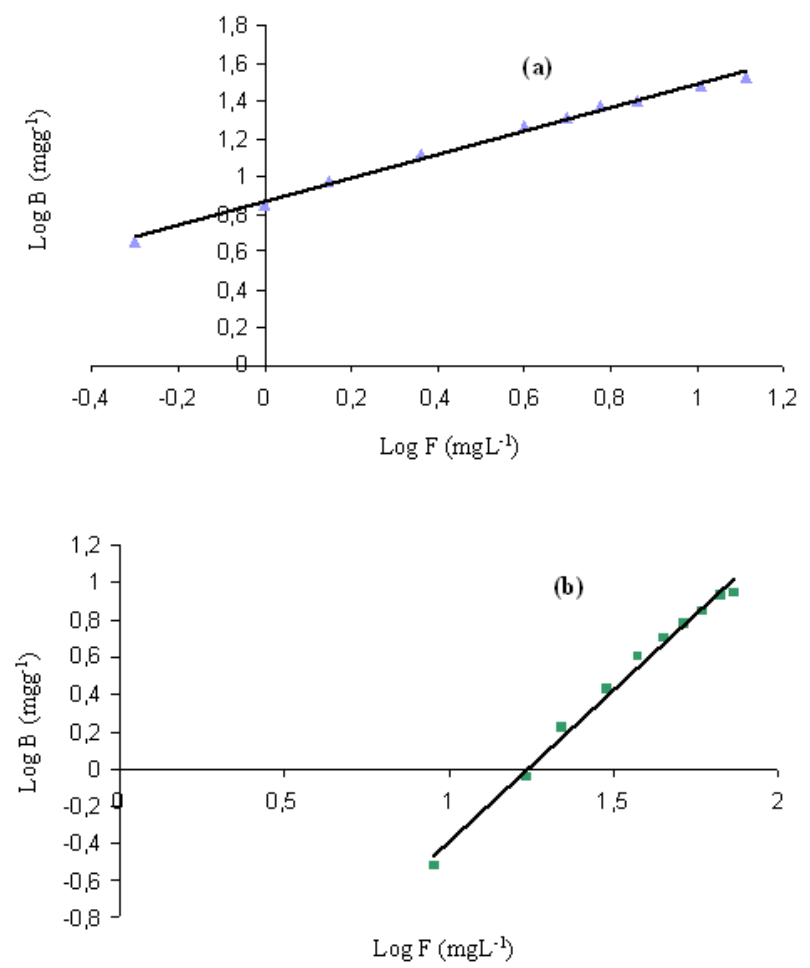

Fig. (5). Freundlich isotherm of ibuprofen adsorption on MIP (a) and NIP (b). Experiments were carried out in batch mode using $30 \mathrm{mg}$ of polymer and $10 \mathrm{~mL}$ of ibuprofen $\left(\mathrm{AcN} / \mathrm{H}_{2} \mathrm{O}: 1 / 9(v / v)\right)$. Samples were agitated for $4 \mathrm{~h}$ at $25^{\circ} \mathrm{C}$.

Table 1. Freundlich Parameters for the MIP and the NIP (see Eq. (2) and Eq.(3))

\begin{tabular}{|c|c|c|c|}
\hline Polymer & $\boldsymbol{R}^{2}$ & $\boldsymbol{m}$ & $\boldsymbol{a}$ \\
\hline \hline MIP & 0.993 & 0.621 & 1353 \\
\hline NIP & 0.995 & 0.732 & 1778 \\
\hline
\end{tabular}

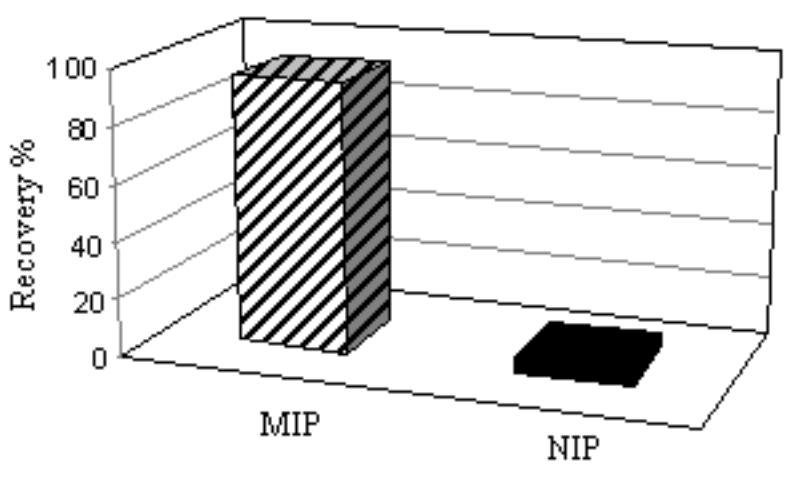

Fig. (6). Recoveries of ibuprofen from standard solution using MIP and NIP extraction.

For further characterization of the synthesized MIP, its capacity was evaluated. The capacity of a MIP corresponds to the maximum amount of a compound that can be retained on the MIP in a given conditions (nature and volume of the 
percolated solvents). So, the determination of the capacity was investigated by measuring the recoveries on the MIP for different ibuprofen concentrations prepared in $\mathrm{AcN} / \mathrm{Water}$ $(1 / 9(\mathrm{v} / \mathrm{v}))$ mixture. Regarding the importance of the washing procedure, AcN containing 1\% TEA was investigated to ensure a specific retention of ibuprofen on MIP. The performance of this washing step was also verified by carrying out the same experiments on the NIP.

Fig. (8) shows related recovery curves obtained with ibuprofen MIP and the NIP. As can be seen from the curve related to MIP, an important linear part was obtained for the adsorbed quantity of ibuprofen. This linearity was extended to an adsorbed amount of $70 \mu \mathrm{g}$ with a correlation coefficient of 0.999 . This amount allows extraction recoveries more than $90 \%$. Beyond this quantity $(70 \mu \mathrm{g})$, a saturation plateau was reached and this value defines the upper limit of the concentration range allowing quantitative ibuprofen extraction. This amount corresponds to ibuprofen capacity of $1.45 \mu \mathrm{mol} \mathrm{g}{ }^{-1}$ of the synthesized MIP. This value is within the range to other values obtained with other MIPs prepared with the non-covalent procedure and their capacities were between 1 and $40 \mu \mathrm{mol} \mathrm{g}^{-1}[3,23]$. Moreover, for the NIP, a low capacity of ibuprofen was measured. This confirms the specificity of the binding sites taking part in the determination of the capacity of the MIP. For quantities higher than $70 \mu \mathrm{g}$, the MIP still retains ibuprofen but with lower recoveries, and this decrease can be explained by the saturation of the specific binding sites.

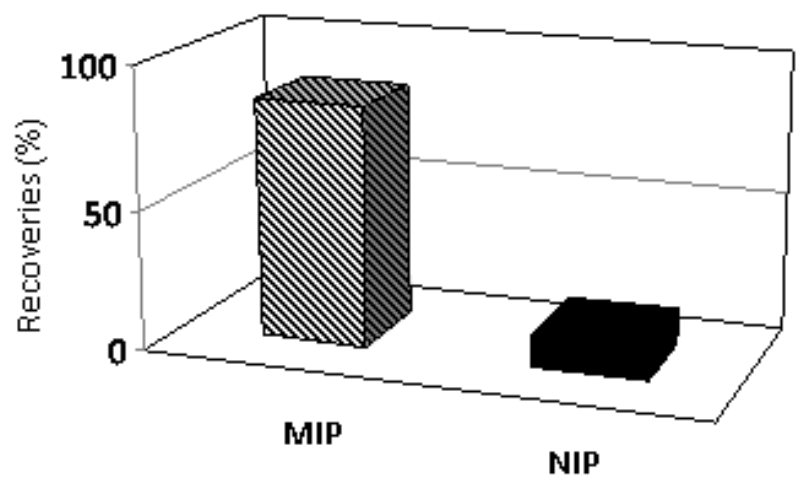

Fig. (7). Recoveries of ibuprofen from urine sample by MIP and NIP.

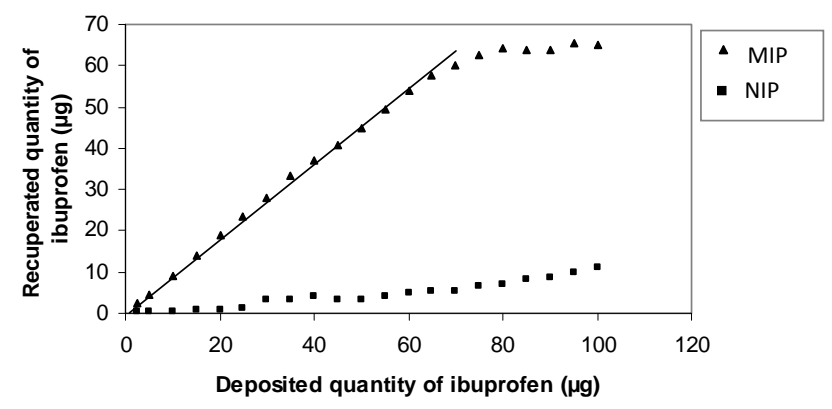

Fig. (8). Relative recovery curves obtained after the percolation of $0.5 \mathrm{~mL}$ of $\mathrm{AcN} / \mathrm{H}_{2} \mathrm{O}(1 / 9(\mathrm{v} / \mathrm{v}))$ spiked with increasing amounts of ibuprofen on the MIP and the NIP (200mg).

\subsection{Selectivity of Solid Phase Extraction}

The selectivity of the MIP for ibuprofen was investigated using ketoprofen and naproxen as interfering compounds. Chromatographic results (Fig. 9) showed the separation of

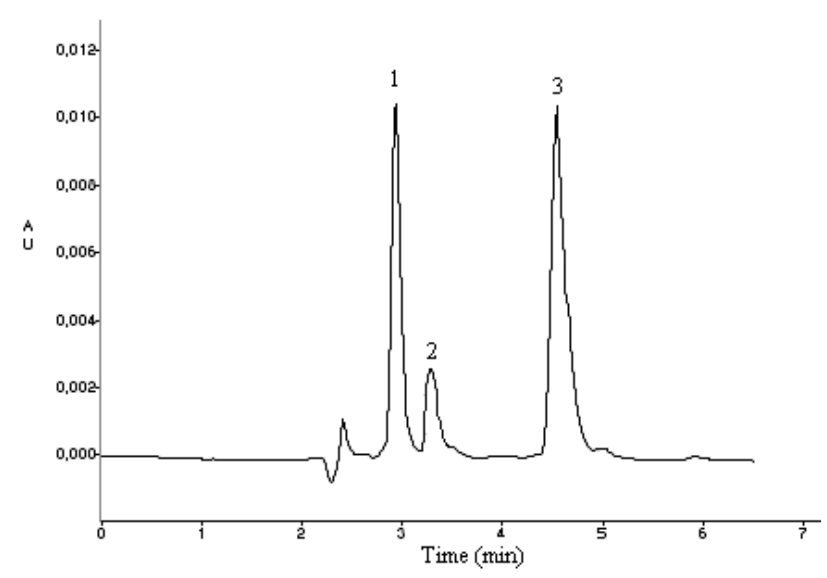

(a)

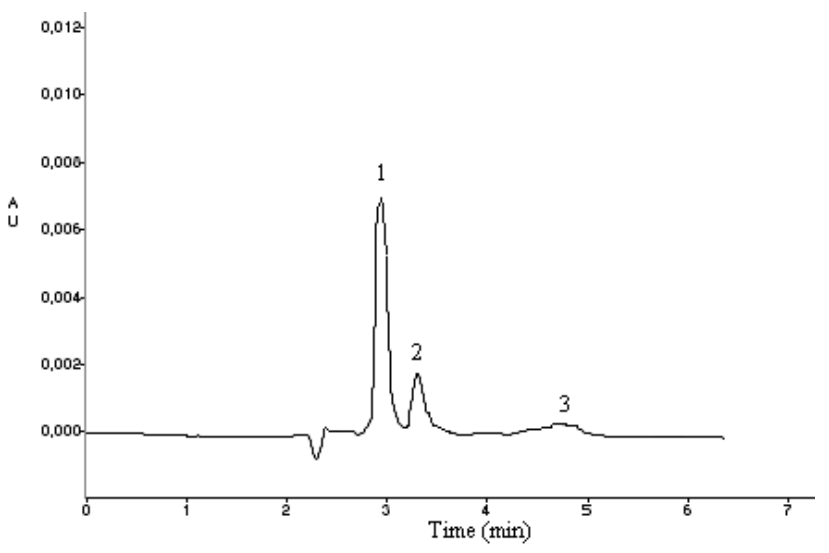

(b)

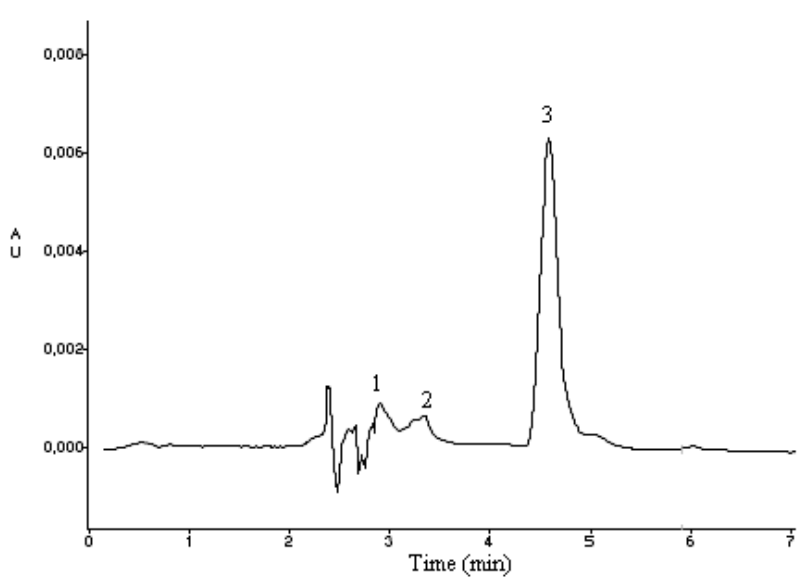

(c)

Fig. (9). Chromatograms of standard mixture (a): Initial solution before MIP-SPE (b): Solution after MIP-SPE; (c) Solution after washing with acetonitrile containing $1 \%$ triethylamine and elution with methanol. 
ibuprofen, ketoprofen and naproxen standard mixture before MIP-SPE and after MIP-SPE. These results showed the selectivity of the chromatographic method as well as the selectivity of the MIP cartridge. Fig. (10) shows the recovery of ibuprofen and its analogues [ketoprofen and naproxen]. The extraction selectivity of MIP for ibuprofen was higher than that obtained for NIP. In contrast, recoveries of the other two compounds were more lower ; $11 \%$ for ketoprofen and $28 \%$ for naproxen. These results could be explained by the fact that the structure of both molecules, ketoprofen and naproxen, contain two aromatic rings. Furthermore, the molecular volume of ketoprofen is significantly larger than that of naproxen (ketoprofen having a molecular volume of 178.4 Angstrom $\left(\mathrm{A}^{\circ}\right)$ and naproxen being $\left.151 \mathrm{~A}^{\circ}\right)$. In the other hand, the molecular volume of ibuprofen is $149.8 \mathrm{~A}^{\circ}$ [18]. According to this, the structure of naproxen is more similar to ibuprofen and this is in agreement with recovery results (Fig. 9).

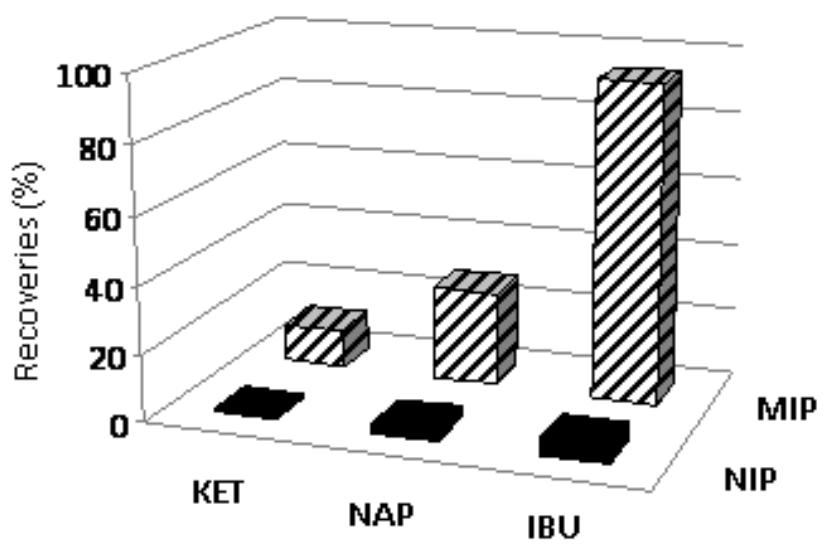

Fig. (10). Recovery of ketoprofen, naproxen and ibuprofen by the MIP and NIP by solid phase extraction. Concentration of each compound was $20 \mathrm{mg} \mathrm{L}^{-1}$. Peaks: 1: Naproxen, 2: Ketoprofen, 3: Ibuprofen. Chromatographic condition as indicated in the experimental part.

\subsection{Analysis of Urine Samples}

To investigate the ability of the SPE method to extract ibuprofen from biological samples, drug free urine samples were obtained from healthy volunteers. They were treated by $\mathrm{AcN}$ and spiked with ibuprofen at a concentration of $20 \mu \mathrm{g}$ $\mathrm{mL}^{-1}$ and then percolated through the MIP after conditioning. After a washing step, ibuprofen was recovered with methanol. The concentration of ibuprofen found after MIP extraction was approximately $17 \mu \mathrm{g} \mathrm{mL} \mathrm{m}^{-1}$ and after NIP extraction was approximately $2.4 \mu \mathrm{g} \mathrm{mL}^{-1}$. Fig. (9) shows that ibuprofen was selectively extracted from urine samples. The recovery of ibuprofen with MIP was $85 \%$ where as for NIP was only $12 \%$. As can be seen from these results, the recovery percent was higher than that of the NIP. The repeatability of spiked urine samples $\left(10,20\right.$ and $50 \mu \mathrm{g} \mathrm{mL} \mathrm{m}^{-1}$ of ibuprofen) expressed as RSD $(n=9)$ was less than $3.5 \%$. These results indicate that MIP has higher efficiency than the NIP.

\section{CONCLUSION}

The potential of MIPs for selective extraction of ibuprofen from urine samples was demonstrated according to the results obtained for the MIP developed for ibuprofen and applied to urine samples. Also, the selectivity over analogues from the same family of NSAID ketoprofen and naproxen was successfully investigated. The percentage of rebinding and selectivity were assessed by solid phase extraction and a specific adsorption capacity of $1.45 \mu \mathrm{mol} \mathrm{g}^{-1}$ of ibuprofen on MIP was measured. The ibuprofen MIP was then directly used to selectively extract the target drug from human urine samples with an extraction recovery of $85 \%$.

\section{REFERENCES}

[1] Michael, A.; Monaco, J. Frequently prescribed medications, Johns and Bartlett Learning: Sudbury, MA, 2010.

[2] Diane S. A.; Samantha J. V. Drug Therapy in Nursing, $3^{\text {ed }}$ ed; Wolters Kluwer Health, Lippincot Williams and Wilkins: Philadelphia, PA, 2009.

[3] Chapuis, F.; Mullot, J.; Pichon, V.; Tuffal, G.; Hennion. M. Molecularly imprinted polymers for the clean-up of a basic drug from environmental and biological samples. J. Chromatogr. A., 2006, $1135,127$.

[4] Pichon, V.; Haup, K. Affinity separations on molecularly imprinted polymers with special emphasis on solid- phase extraction. J. Liq. Chromatogr. Relat. Technol., 2006, 29, 989.

[5] Haginaka, J. Uniform-sized molecularly imprinted polymers for 2arylpropionic Acid derivatives selectively modified with hydrophilic external layer and their applications to direct serum injection analysis. Trends Anal. Chem., 2004, 24, 407.

[6] He, Y.; Pan, J.; Li, K.; Liu. F. Application of molecularly imprinted polymers to solid-phase extraction of analytes from real samples. $J$. Biochem. Biophys. Meth., 2007, 70, 133.

[7] Nakamura, M.; Ono, M.; Nakajima, T.; Ito, Y.; Aketo, T.; Haginaka. J. Uniformly sized molecularly imprinted polymer for atropine and its application to the determination of atropine and scopolamine in pharmaceutical preparations containing Scopolia extract. J. Pharm. Biomed. Anal., 2005, 37, 231.

[8] Abdel-Rehim, M.; Andersson, L.; Altun, Z.; Blomberg, L. Microextraction in packed syringe online with liquid chromatography-tandem mass spectrommetry: molecularly imprinted polymer as packing material for MEPS in selective extraction of Ropivacaine from plasma. J. Liq. Chromatogr. Relat. Technol., 2006, 29, 1725.

[9] Sanbe, H.; Haginaka, J. Restricted access media-molecularly imprinted polymer for propranolol and its application to direct injection analysis of $\beta$-blockers in biological fluids, Analyst., 2003, 128,593 .

[10] Caro, E.; Marce, R.; Cormarck, P.; Sherrington, D.; Borrull. F. A new molecularly imprinted polymer for the selective extraction of naproxen from urine samples by solid-phase extraction. J. Chromatogr. B., 2004, 813, 137.

[11] Wu, S.; Lai, E.; Mayer. P. Molecularly imprinted solid phase extraction-pulsed elution-mass spectrometry for determination of cephalexin and $\alpha$-aminocephalosporin antibiotics in human serum. J. Pharm. Biomed. Anal., 2004, 36, 483.

[12] Sellergren. B. Direct drug determination by selective sample Enrichment on an imprinted polymer. Anal. Chem., 1994, 66, 1578.

[13] Brambilla, G.; Fiori, M.; Rizzo, B.; Crescenzi, V.; Masci, G. Use of molecularly imprinted polymers in the solid-phase extraction of clenbuterol from animal feeds and biological matrices. $J$. Chromatogr. B., 2001, 759, 27.

[14] Berggren, C.; Bayoudh, S.; Sherrington, D.; Ensing, J. Use of molecularly imprinted solid-phase extraction for the selective clean-up of clenbuterol from calf urine. J. Chromatogr. A., 2000, $889,105$.

[15] Hu, S.; Li, L.; He X.-W. Comparison of trimethoprim molecularly imprinted polymers in bulk and in sphere as the sorbent for solidphase extraction and extraction of trimethoprim from human urine and pharmaceutical tablet and their determination by highperformance liquid chromatography. Anal. Chim. Acta, 2005, 537, 215.

[16] Snyder, L.; Kirkland, J.; Dolan, J. Introduction to modern liquid chromatography. John Wiley, USA, 2009.

[17] Pierce D.; Zhao J. Trace Analysis with Nanomaterials. John Wiley, USA, 2010. 
[18] Farrington, K.; Regan, F. Investigation of the nature of MIP recognition : the development and characterization of a MIP for ibuprofen. Biosens. Bioelectron., 2007, 22, 1138.

[19] Monser, L.; Adhoum, N. Tartrazine modified activated carbon for the removal of $\mathrm{Pb}(\mathrm{II}), \mathrm{Cd}(\mathrm{II})$ and $\mathrm{Cr}(\mathrm{III})$. J. Hazard. Mater., 2009, $161,263$.

[20] Umpleby, R.; Baxter, S.; Rampey, A.; Rushton, G.; Chen, Y.; Shimizu, K. Characterization of the heterogeneous binding site affinity distribution in molecularly imprinted polymers. $J$. Chromatogr B., 2004, 804, 141.
[21] Rushton, G.; Karns, C.; Shimizu, K. A critical examination of the use of the Freundlich isotherm in characterizing molecularly imprinted polymers (MIPs). Anal. Chim. Acta, 2005, 528, 107.

[22] Umpleby, R.; Baxter, S.; Bode, M.; Berch, J.; Shah, R.; Shimizu,

$\mathrm{K}$. Application of the Freundlich adsorption isotherm in the characterization of molecularly imprinted polymers. Anal. Chim. Acta., 2001, 435, 35.

[23] Chapuis, F.; Pichon. V. Molecularly imprinted polymers for selective extraction of analytes from biological samples. Ann. Toxicol. Anal., 2007, 19, 239.

(C) Lagha et al.; Licensee Bentham Open.

This is an open access article licensed under the terms of the Creative Commons Attribution Non-Commercial License (http://creativecommons.org/licenses/by$\mathrm{nc} / 3.0 /$ ) which permits unrestricted, non-commercial use, distribution and reproduction in any medium, provided the work is properly cited. 